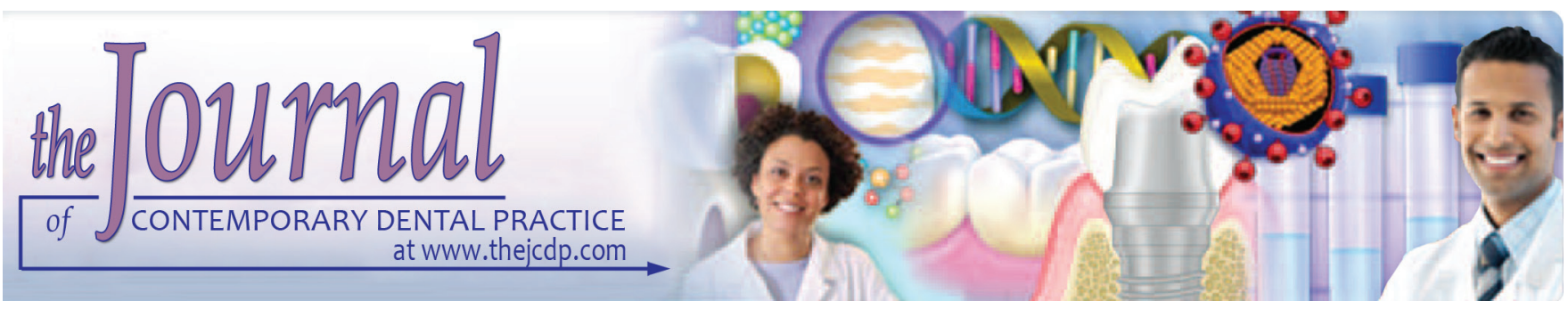

\title{
Effect of Mouthrinses containing Olive Oil, Fluoride, and Their Combination on Enamel Erosion: An in vitro Study
}

\author{
${ }^{1} \mathrm{HP}$ Vivek, ${ }^{2} \mathrm{GM}$ Prashant, ${ }^{3}$ Seema Geetha, ${ }^{4}$ Sabari Chandramohan, ${ }^{5} \mathrm{Md}$ Imranulla, ${ }^{6} \mathrm{~PB}$ Srinidhi
}

\begin{abstract}
Aim: The aim of the study was to evaluate the effect of mouthrinses containing olive oil, fluoride, and their combination on enamel erosion.
\end{abstract}

Materials and methods: An in vitro study of 45 enamel specimens, which were prepared from 45 extracted teeth, was employed. Each specimen was subjected to 10 alternative demineralization and remineralization cycles. Remineralizing cycle includes 5 minutes exposure with one of the mouthrinse, and demineralizing cycle includes 3 minute exposure to $1 \%$ citric acid. Mean surface roughness ( $\mathrm{Ra}$ ) was measured from surfometry before and after cycles. Statistical tests used were Student's unpaired t-test and one-way analysis of variance (ANOVA), followed by Tukey's post hoc test.

Results: Among the three mouthrinses, Listerine and Xerostom showed maximum protection against erosion on enamel. The $2 \%$ olive oil mouthrinse showed the least protection against erosion on enamel.

Conclusion: The study indicated that the Listerine and Xerostom mouthrinses are valuable preventive measures.

Clinical significance: Mouthrinses are effective for lessening erosive demineralization and in aggregating remineralization of tooth surfaces which are the important factors to prevent enamel erosion.

Keywords: $2 \%$ olive oil, Enamel, Erosion, Mouthrinse, Xerostom.

How to cite this article: Vivek HP, Prashant GM, Geetha S, Chandramohan S, Imranulla M, Srinidhi PB. Effect of Mouthrinses

1,2,5,6 Department of Public Health Dentistry, College of Dental Sciences, Davangere, Karnataka, India

${ }^{3,4}$ Department of Periodontics, Sri Sankara Dental College Thiruvananthapuram, Kerala, India

Corresponding Author: HP Vivek, Department of Public Health Dentistry, College of Dental Sciences, Davangere, Karnataka India, Phone: +918095306448, e-mail: hpvivek_goku@yahoo. com containing Olive Oil, Fluoride, and Their Combination on Enamel Erosion: An in vitro Study. J Contemp Dent Pract 2018; 19(2):130-136.

Source of support: Nil

Conflict of interest: None

\section{INTRODUCTION}

Dental erosion is defined as an irreversible loss of dental hard tissues due to a chemical process without the involvement of microorganisms. ${ }^{1}$ This process may be caused by intrinsic or extrinsic agents or factors. Extrinsic agents or factors include acidic foods, drinks, substances, and acidic exposure from environmental agents, ${ }^{2}$ while intrinsic agents or factors include frequent backflow from esophagus as part of the eating disorders, such as bulimia nervosa or anorexia or due to the throwing up of the gastrointestinal insides during pregnancy. ${ }^{3,4}$

Dental erosion is an important factor when considering in maintaining long-term dental health. ${ }^{2}$ An important factor concerning enamel erosion is to find substances that help in prevention of demineralization and facilitate remineralization. ${ }^{5,6}$ It has been revealed in numerous studies that professionally applied fluoride has an effect in lowering erosive demineralization and in promoting remineralization. ${ }^{7,8}$ Especially when professionally applied fluoride is combined with fluoridated mouthrinse, fluoridated gel, and fluoride toothpaste, it might be effective in reducing the development of the lesions. ${ }^{9}$

Although application of fluoride in reducing the erosion is still debatable, previous studies have shown the possible protective effects of fluoride on erosion. ${ }^{10}$

The preventive effect of fluoride is mainly due to the formation of a calcium fluoride $\left(\mathrm{CaF}_{2}\right)$ layer on the enamel, which acts as a reservoir for fluoride. During 
an acid attack, fluoride released from the reservoir is incorporated into the outer surface of enamel by forming fluoroapatite crystal resulting in a reduced susceptibility to acid. ${ }^{11-13}$

Phospholipids play an important part during odontogenesis and remain in mature dental hard tissue. They are second largest organic molecules after protein in enamel. The amount of lipid present in teeth is found to be $0.15 \% \mathrm{w} / \mathrm{w}$ for enamel. ${ }^{14,15}$ Only slight attention has been focused on the role of lipids in erosion.

Olive oil is a product which is extensively used in the preparation of food. Oleic acid, which is a monounsaturated fatty acid, is responsible for various beneficial effects, such as prevention of arteriosclerosis, increase in high-density lipoproteins, and decrease in low-density lipoproteins. ${ }^{16,17}$

The $2 \%$ olive oil with fluoride mouthrinse was developed as saliva alternative for patients suffering from dry mouth, it would be curious to assess if olive oil offers any defense against erosion when used as olive-oil-containing mouthrinse.

Considering the present knowledge on dental erosion and its increase steadily in the past few decades, ${ }^{5}$ preventive agents are needed. Several agents have been studied to prevent the development of erosion, which includes topical fluoride application and alteration in acidic beverages. $^{6}$

Therefore, this study was conducted to know the outcome of $2 \%$ olive oil mouthrinse and $2 \%$ olive oil with fluoride mouthrinses (Xerostom) on lesion progression under several demineralization conditions in enamel using sodium fluoride (Listerine) mouthrinse as a control.

\section{MATERIALS AND METHODS}

The mouthrinses used in the study were:

- Xerostom mouthrinse (containing $2 \%$ olive oil with fluoride)

- $2 \%$ olive oil mouthrinse

- Listerine mouthrinse (sodium fluoride as a control).

All the mouthrinses used in the study were purchased from Davangere which were commercially available, except for $2 \%$ olive oil which was prepared.

\section{Preparation of $2 \%$ Olive Oil Mouthrinse}

About $2 \mathrm{~mL}$ of the $100 \%$ extra virgin olive oil was mixed in $98 \mathrm{~mL}$ of distilled water and gently stirred with a stirrer till it was completely mixed. The preparation also contained distilled water, sorbitol (sweetener), sodium saccharin, glycerine, aroma, buffer, preservative, coloring agent, and surfactant. The prepared mouthrinse was then transferred to amber-colored plastic bottles.

\section{Tooth Selection}

\section{Inclusion Criteria}

- Healthy first and/or second upper and lower premolars or molars (free from caries) were extracted for orthodontic reasons under local anesthesia.

\section{Exclusion Criteria}

- Premolars of adults and children with medical conditions.

- First and/or second upper and lower premolars or molars with signs of decay, fracture, wasting disease, and filling or any abnormality.

\section{Preparation of Specimen and Allocation}

Specimens were prepared from teeth which fulfilled the inclusion and exclusion criteria. Forty-five extracted human premolars/molars were collected. All the teeth were thoroughly cleaned and polished and then stored in distilled water until use. The tooth was splitted at $2 \mathrm{~mm}$ below cementoenamel junction using double-sided diamond disk operated in a micromotor handpiece with water coolant. The crown was placed into the chemically activated resin in a silicon matrix and a part of enamel exposed. The exposed enamel surface of each specimen was polished using a circular polishing buff with pumice to obtain a smooth, standardized surface, which is necessary for surfometric analysis. After sectioning, the test specimens are kept in distilled water until further analysis.

Forty-five enamel specimens were randomly divided into three groups and were coded to ensure blinding.

- Group I: Experimental group containing 15 enamel specimens exposed to commercially available $2 \%$ olive oil with fluoridated mouthrinse (Xerostom mouthrinse).

- Group II: Experimental group containing 15 enamel specimens exposed to $2 \%$ olive oil mouthrinse.

- Group III: Control group containing 15 enamel specimens exposed to commercially available sodium fluoride mouthrinse (Listerine mouthrinse).

\section{Surfometric Measurement}

Erosion in terms of Ra was calculated using Digital Surfometry (Mitutoyo surftest SJ-201P). Surfometry, also known as profilometry, has been extensively used to characterize Ra due to erosion. ${ }^{4}$ The instrument uses a metallic stylus with a diameter of 0.5 inch that runs across the specimen at a rate of around $0.01 \mathrm{inch} / \mathrm{s}(0.25 \mathrm{~mm} / \mathrm{s})$ and force of $4 \mathrm{mN}$.

To determine the effect of erosion, a portion of the specimen surface was secured with adhesive tape. The 
unsecured surface area was in contact with the test agents and erosive agent, thus giving an assessment between secured and unsecured areas.

Before study, baseline reading was recorded to determine referral areas for calculation of surface roughness. Four readings were performed at intervals of $0.4 \mathrm{~cm}$. The lines were located at $0.2,0.6,1,1.4$, and $1.8 \mathrm{~cm}$ from the end of the specimen. The mean was calculated by the software SURFPAK-SJ. The tapes were placed on both sides and covered $1 \mathrm{~cm}$ of the specimen from each side. After testing, the tapes were detached, and the specimen was analyzed. The data obtained from surfometry were recorded in micrometers.

\section{Study Design}

Specimens were subjected to 10 alternative cycles of mineralization and erosion. The duration of mineralization cycle was 5 minutes with the test agents. After the cycle, specimens were washed under running water and placed in artificial saliva for 30 minutes. Erosion sequence was done by placing specimens in $1 \%$ citric acid ( $2.3 \mathrm{pH}$ for 3 minutes).

\section{Data Compilation and Presentation}

Data were collected, and a master chart was prepared. The data were subdivided and distributed meaningfully and presented as individual tables along with graphs.

\section{Statistical Analysis}

Data collected from the experiment were analyzed using Statistical Package for the Social Sciences, version 22.0. The recorded values are presented as the mean \pm standard deviation (SD). Data evaluation was done by applying appropriate statistical tests. Tests applied in the study were

- Erosion in terms of surface roughness in enamel at baseline and after remineralization and demineralization cycles was compared with Student's t-test (intragroup or within-group comparison).

- Erosion in terms of surface roughness between the three mouthrinses was compared by ANOVA followed by Tukey's post hoc tests for pairwise comparison. For all the tests, $\mathrm{p} \leq 0.05$ was considered statistically significant.

\section{RESULTS}

The present study was conducted with an objective of evaluating the effect of $2 \%$ olive oil, $2 \%$ olive oil and fluoride, and fluoride mouthrinses on lesion progression under several demineralization conditions in enamel. The study included 45 enamel samples. The samples met all inclusion criteria. The comparisons of the erosion in terms of surface roughness $(\mu \mathrm{m})$ were done before and after mineralization cycles.

Table 1 summarizes intragroup comparison of the mean surface roughness $(\mu \mathrm{m})$ on enamel of three different mouthrinse groups before and after mineralization cycles.

The mean surface roughness of enamel in Xerostom mouthrinse group before and after mineralization cycles was $1.27 \pm 0.006$ and $1.30 \pm 0.015$ respectively, as shown in Graph 1. Results were highly significant ( $p=0.001)$.

The mean surface roughness of enamel in $2 \%$ olive oil mouthrinse group before and after mineralization cycles was $1.27 \pm 0.004$ and $1.56 \pm 0.011$ respectively, as shown in Graph 2. Results were highly significant $(p=0.001)$.

The mean surface roughness of enamel in Listerine mouthrinse group before and after mineralization cycles was $1.27 \pm 0.005$ and $1.32 \pm 0.02$ respectively, as shown in Graph 3. Results were highly significant ( $p=0.001)$.

Table 2 and Graph 4 show intergroup comparison of the mean surface roughness $(\mu \mathrm{m})$ of three different mouthrinse groups on enamel before and after mineralization cycles.

There was no statistically significant change from the values obtained in groups before mineralization cycles $(p>0.05)$.

There was a statistically significant change from the values obtained in groups after mineralization cycles $(p<0.05)$. Applying Tukey's post hoc analysis, more surface roughness was seen in $2 \%$ olive oil mouthrinse group than in Xerostom mouthrinse group and Listerine mouthrinse group.

\section{DISCUSSION}

Mouthwashes have been used for decades for cosmetic and medicinal purposes, but it is only in past few years that the reason behind the use of the components has been experimented under scientific research and clinical trials. Although topical fluoride held its place for many years as the frontline for antierosive agents, the introduction of mouthrinses containing sodium fluoride has been

Table 1: Intragroup comparison of the mean surface roughness $(\mu \mathrm{m})$ on enamel of three different mouthrinse groups before and after mineralization cycles

\begin{tabular}{|c|c|c|c|c|}
\hline & & Before & After & \\
\hline Groups & $n$ & Mean $\pm S D$ & Mean $\pm S D$ & $p$-value \\
\hline $\begin{array}{l}\text { Xerostom } \\
\text { mouthrinse }\end{array}$ & 15 & $1.27 \pm 0.006$ & $1.30 \pm 0.015$ & $0.001 \mathrm{HS}$ \\
\hline $\begin{array}{l}2 \% \text { olive oil } \\
\text { mouthrinse }\end{array}$ & 15 & $1.27 \pm 0.004$ & $1.56 \pm 0.011$ & $0.001 \mathrm{HS}$ \\
\hline $\begin{array}{l}\text { Listerine } \\
\text { mouthrinse }\end{array}$ & 15 & $1.27 \pm 0.005$ & $1.32 \pm 0.026$ & $0.001 \mathrm{HS}$ \\
\hline
\end{tabular}

HS: Highly significant 


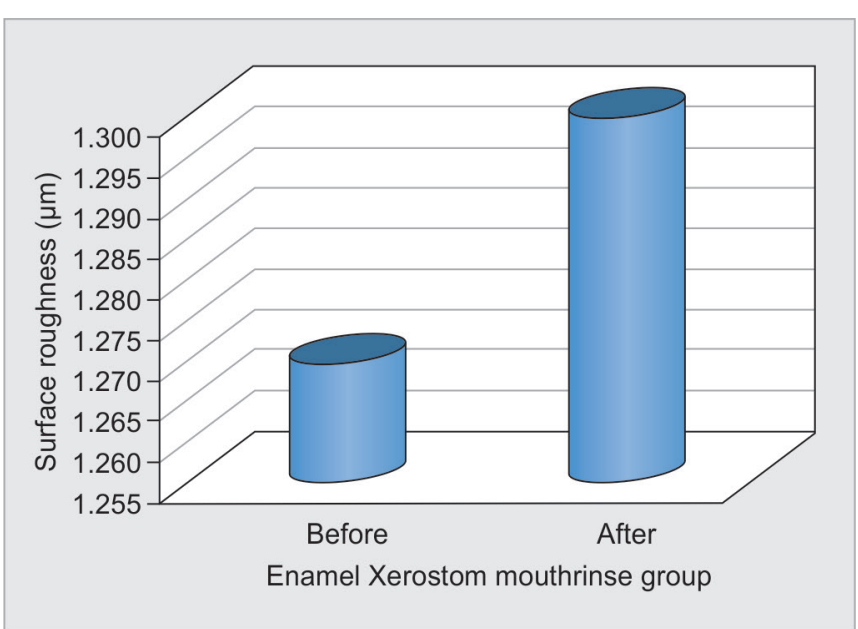

Graph 1: Mean surface roughness of enamel on Xerostom mouthrinse group before and after demineralization

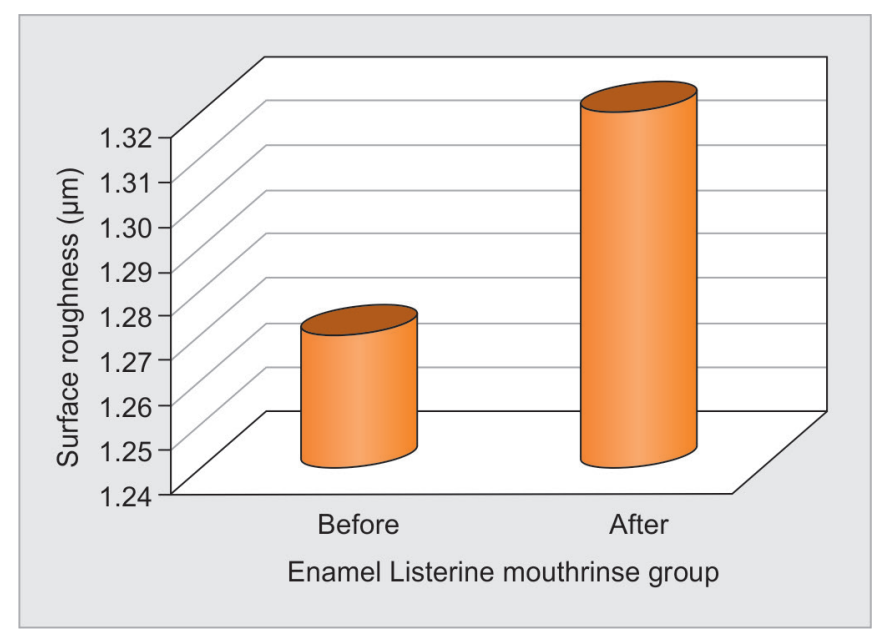

Graph 3: Mean surface roughness of enamel on Listerine mouthrinse group before and after demineralization

Table 2: Intergroup comparison of the mean surface roughness $(\mu \mathrm{m})$ of three different mouthrinse groups on enamel before and after mineralization cycles

\begin{tabular}{lll}
\hline & Before & After \\
\cline { 2 - 3 } Groups & Mean \pm SD & Mean \pm SD \\
\hline Xerostom mouthrinse $^{1}$ & $1.27 \pm 0.006$ & $1.30 \pm 0.015$ \\
2\% olive oil mouthrinse $^{2}$ & $1.27 \pm 0.004$ & $1.56 \pm 0.011$ \\
Listerine mouthrinse $^{3}$ & $1.27 \pm 0.005$ & $1.32 \pm 0.026$ \\
Analysis of variance & & \\
F-value & 0.59 & 895.57 \\
p-value & $0.555 \mathrm{NS}$ & $0.001 \mathrm{HS}$ \\
Tukey's post hoc & & $2>1.3$ \\
\hline
\end{tabular}

NS: Not significant; HS: Highly significant

a key advancement in the investigation for a chemical means to prevent erosion. ${ }^{11}$ As erosion cannot be stopped completely with the use of topical fluoride in daily usage, there is a growing interest for recognizing other substances or ingredients that might help in decreasing

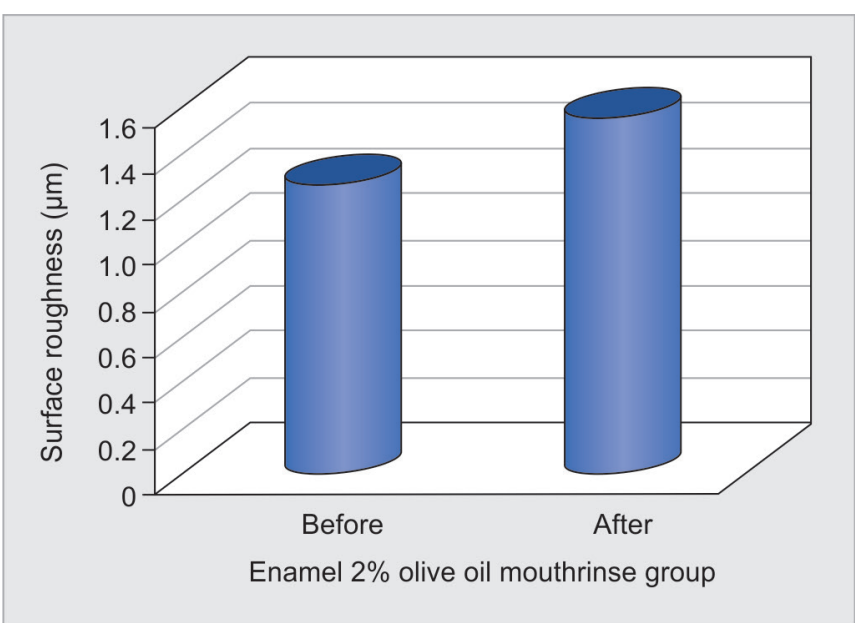

Graph 2: Mean surface roughness of enamel on $2 \%$ olive oil mouthrinse group before and after demineralization

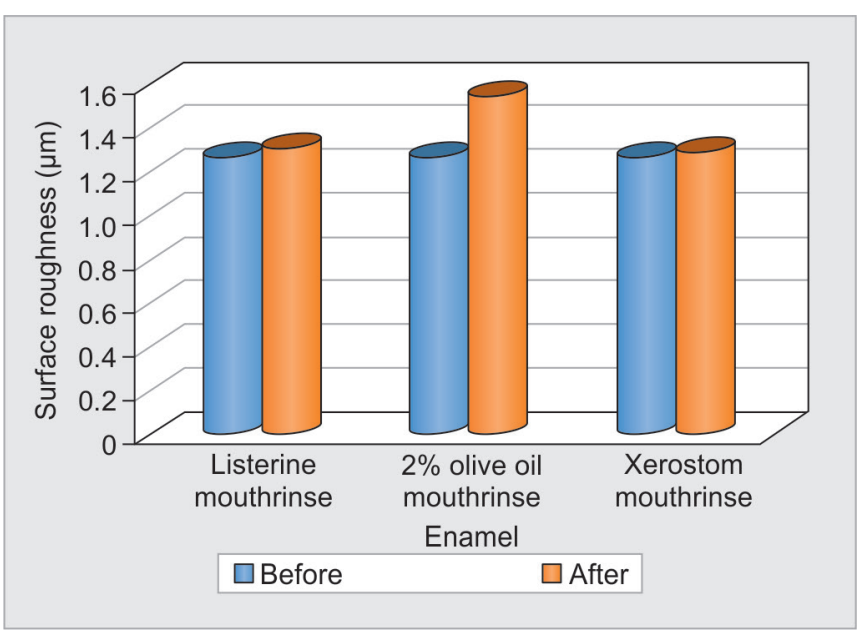

Graph 4: Comparison of the mean surface roughness of three different mouthrinses on enamel before and after demineralization

erosion or increasing the antierosive effect, particularly in patients who have Xerostomia., ${ }^{9} 14$

The present in vitro study gave an evidence that $2 \%$ olive oil or $2 \%$ olive oil with fluoride is useful in preventing erosion. Therefore, intense erosion circumstances (3 minutes in citric acid at $\mathrm{pH} 2.3$ ) were used to emphasize the protecting properties of olive oil or mouthwashes.

Acids in the mouth come from three main sources: Produced in mouth by acidogenic bacteria, extrinsic acids consumed as diet, and intrinsic acids through vomiting of gastric contents. Acids of bacterial origin cause decay, while intrinsic and extrinsic acids cause erosion. ${ }^{18,19}$

One of the chief causes of erosion is the drinking of acidic or soft drinks, including carbonated drinks (Coke, pH 2.7; Pepsi, pH 2.7; and Sprite, $\mathrm{pH} 2.6$ ), ${ }^{20,21}$ fruit juices (orange juice, $\mathrm{pH} 3.4$; apple juice, $\mathrm{pH} 3.4$; and grape juice, $\mathrm{pH}$ 3.4), and sport drinks (Red Bull, $\mathrm{pH}$ 3.4; Gatorade, $\mathrm{pH}$ 3.3; and wine, $\mathrm{pH}$ 2.3-3.8). ${ }^{22}$ To maintain a fresh and bubbly mouthfeel and to stop the growth of 
microorganisms in drinks, all the soft drinks are acidic $(\mathrm{pH}<4.0)$ in nature. Besides acidic drinks, many solid and semisolid foodstuff are also acidic in nature. Fruits, such as apples, blueberries, grapes, oranges, peaches, and pineapples have low $\mathrm{pH}$ values (2-3), and other foodstuffs, such as cranberry sauce, fruit jams/jellies, ketchup, mustard, and tomatoes have also low $\mathrm{pH}$ values. ${ }^{23}$ The source of intrinsic acids in the oral cavity is mainly from the reflux of the gastric contents through the esophageal tract. ${ }^{24}$ Voluntary vomiting of gastric contents (rumination) has been recorded in some people as a possible reason for dental erosion. ${ }^{25,26}$ Hence, erosion treatments were done by immersing in citric acid ( $\mathrm{pH}$ 2.3) to simulate the condition during intake of acidic foods or beverages, mostly having $\mathrm{pHs}$ from 2 to 4 .

Presently, there is no typical procedure to perform erosion experiments in general, and in particular, for testing antierosive agents. ${ }^{27}$ This study setting was modified to satisfactorily test the effects of antierosive agents. Many procedures were used to test erosion in vitro which includes (1) surface hardness and nanoindentation techniques, (2) profilometry, (3) microradiography, (4) chemical analysis, (5) microscopy techniques, (6) atomic force microscopy, (7) secondary ion mass spectroscopy, and (8) quantitative light-induced fluorescence. ${ }^{4}$

Profilometry, also known as surfometry, is widely used to check the surface roughness caused by erosion. Profilometry is an easy and rapid method for measuring the somewhat large area of enamel. It is used to study the erosive potential of numerous products in vitro, such as fruit juice, fizzy drinks, alcopops, white wines, ciders, teas, mouthrinses, and various acidic drinks. ${ }^{28,29}$ Since erosion in terms of surface roughness is checked rather than softening, profilometry was used to check erosion. ${ }^{4}$

Fluorides are abundantly used in oral health products including the mouthrinses. Sodium fluoride mouthrinses are effective in reducing caries and also as an antierosive agent. ${ }^{26}$ After application, fluoride on the enamel surface increases. This occurrence was probably related to the formation of $\mathrm{CaF}_{2}$-like materials on the enamel surface. ${ }^{6}$

Dental erosion is more serious in patients who are suffering from dry mouth, and there is a deficiency of natural saliva buffer capability to prevent erosion. As erosion cannot be controlled entirely with the use of fluoride in daily dosage, there is a growing demand for recognizing agents or constituents that might prevent erosion or increase the antierosive effect.

Western people are looking on ancient eastern principles for means to expand and energize their lifestyle. Indian civilization is very ancient and rich in resources, such as organic diets, medicinal plants, or herbs. The use of medicinal herbs or plants for treating sicknesses has been common practice in India for ages. In our study, we have selected a fruit oil, olive oil, to study the effect as antierosive mouthwash against enamel.

The study was divided into three groups, each corresponding to a mouthrinse including control. This study was conducted in two phases, i.e., before demineralization and after demineralization with one of the mouthrinses.

In phase I, all the specimens were subjected for baseline analysis of mean Ra by surfometry. Then, the specimens were immersed in respective mouthrinse for 5 minutes followed by 3 minutes in 1\% citric acid and stored in artificial saliva for 60 minutes. This cycle is repeated 10 times. After the cycles, the second phase, i.e., analysis of mean surface roughness, was done.

In the current study, $220 \mathrm{ppm}$ of sodium fluoride $(\mathrm{pH}$ 5.2), used as a mouthrinse, was not found to be effective in completely rescuing the enamel. The results are consistent with the results of Wiegand et al, ${ }^{9}$ Ganss et al, ${ }^{10,26,30}$ Gedalia et al, ${ }^{31}$ and Yu et al. ${ }^{6} \mathrm{CaF}_{2}$-like precipitates, resulting from topical application of sodium fluoride, are easily diffusible under mildly erosive in vitro settings, but are retained for much longer under intraoral acid impact.

The results of the current study show that the use of $2 \%$ olive oil with fluoride mouthwash (Xerostom) before an attack with erosion might reduce the effect. Results were in accordance with the study conducted by Wiegand et al, ${ }^{9}$ who used the bovine enamel, but in our study, we used human enamel. The $2 \%$ olive oil with fluoride helps in decreasing erosion, the shielding effect of this mouthwash would be due to its lipid content. However, along with olive oil another component, such as potassium fluoride or xylitol would have an impact on erosion. Thereby, the ingredients might act additively or combatively in relation to decreasing demineralization.

Xerostom, a mouthrinse containing $2 \%$ olive oil, was first developed to treat patients who were suffering from decreased saliva flow. Reduced saliva flow causes difficulties in talking, chewing, deglutition, altered taste, decay tooth, difficulty in the use of temporary denture, bacterial infections, halitosis, and worsening of oral mucosa which all result in reduced quality of life.

The current study shows that the use of $2 \%$ olive oil mouthrinse has the least effect in controlling the enamel erosion when compared with all three mouthrinses. Results were not consistent with the study conducted by Wiegand et $\mathrm{al}^{9}$ and Buchalla et al. ${ }^{32}$

Chemically, olive oil is a lipid, containing three fatty acids (oleic, palmitic, and linoleic or linolenic) bonded together by glycerol (triglyceride). Pure olive oil has decreased adhesion on enamel surface due to its low separation, particularly in in vivo circumstances, where 
tooth surface was covered with plaque or pellicle. It is expected that the bonding of olive oil to tooth surface might be improved when used as mouthrinse by forming a defensive layer on tooth surface, which acts as a protective layer during erosion. ${ }^{33}$ So these mouth rinses are effective in reducing erosion process and increase remineralization of tooth surfaces.

Dental erosion is an important factor when considering in maintaining long-term dental health. To reduce enamel erosion, it is better to find out the agents that help in prevention of demineralization and facilitate remineralization. These mouthrinses are effective in reducing enamel erosion.

\section{CONCLUSION}

The following conclusions can be drawn out of the present study:

- All the three mouthrinses used in the study (Listerine mouthrinse, $2 \%$ olive oil mouthrinse, and Xerostom mouthrinse), when used as a remineralizing solution for 5 minutes before demineralization, do not completely inhibit the erosion on enamel.

- Within the 4 months of in vitro study, it can be demonstrated that among the tested mouthrinses, Listerine and Xerostom mouthrinses had comparable antierosion properties on enamel. However, $2 \%$ olive oil mouthrinse had the least antierosion property on enamel specimens.

- The two mouthrinses, namely, Listerine and Xerostom, are equivalent in their effectiveness in reducing erosion on enamel specimens. None of them was superior to the other with respect to their antierosion properties. However, $2 \%$ olive oil mouthrinse had the least antierosion property on enamel specimens.

- The findings of the current study suggest that Xerostom mouthrinses offer defense against erosion on enamel. Even though the defensive effect can be noticed under intense erosion conditions of the current study, it can be implied that the effect might be improved during decreased erosive circumstances.

- Overall, the observed protective effect of olive oil mouthrinse although is not significant at $2 \%$ concentration, it might be too early to draw conclusion and hence, it would be interesting to check whether olive oil protects erosion at different concentrations, and thus further research in this field is justified.

\section{REFERENCES}

1. Imfeld T. Dental erosion. Definition, classification and links. Eur J Oral Sci 1996 Apr;104(2 Pt 2):151-155.

2. Lussi A, Jaeggi T, Zero D. The role of diet in the aetiology of dental erosion. Caries Res 2004;38(Suppl 1):34-44.
3. Scheutzel P. Etiology of dental erosion-intrinsic factors. Eur J Oral Sci 1996 Apr;104(2 Pt 2):178-190.

4. Barbour ME, Rees JS. The laboratory assessment of enamel erosion: a review. J Dent 2004 Nov;32(8):591-602.

5. Jaeggi T, Lussi A. Prevalence, incidence and distribution of erosion. Monogr Oral Sci 2006 Feb;20:44-65.

6. Yu H, Attin T, Wiegand A, Buchalla W. Effects of various fluoride solutions on enamel erosion in vitro. Caries Res 2010 Aug;44(4):390-401.

7. Bardow A, Nyvad B, Nauntofte B. Relationships between medication intake, complaints of dry mouth, salivary flow rate and composition, and the rate of tooth demineralization in situ. Arch Oral Biol 2001 May;46(5):413-423.

8. Leung KC, McMillan AS, Leung WK, Wong MC, Lau CS, Mok TM. Oral health condition and saliva flow in southern Chinese with Sjögren's syndrome. Int Dent J 2004 Jun;54(3): 159-165.

9. Wiegand A, Gutsche M, Attin T. Effect of olive oil and an olive-oil-containing fluoridated mouthrinse on enamel and dentin erosion in vitro. Acta Odontol Scand 2007 Nov;65(6): 357-361.

10. Ganss C, Klimek J, Brune V, Schürmann A. Effects of two fluoridation measures on erosion progression in human enamel and dentine in situ. Caries Res 2004 Nov-Dec;38(6):561-566.

11. Lagerweij MD, Buchalla W, Kohnke S, Becker K, Lennon AM, Attin T. Prevention of erosion and abrasion by a high fluoride concentration gel applied at high frequencies. Caries Res 2006 Feb;40(2):148-153.

12. Saxegaard E, Rölla G. Fluoride acquisition on and in human enamel during topical application in vitro. Scand J Dent Res 1988 Dec;96(6):523-535.

13. Wiegand A, Bichsel D, Magalhães AC, Becker K, Attin T. Effect of sodium, amine and stannous fluoride at the same concentration and different $\mathrm{pH}$ on in vitro erosion. J Dent 2009 Aug;37(8):591-595.

14. Lennon AM, Pfeffer M, Buchalla W, Becker K, Lennon S, Attin T. Effect of a casein/calcium phosphate-containing tooth cream and fluoride on enamel erosion in vitro. Caries Res 2006 Feb;40(2):154-157.

15. Featherstone JD, Rosenberg H. Lipid effect on the progress of artificial carious lesions in dental enamel. Caries Res 1984;18(1):52-55.

16. Yaegaki K, Sanada K. Effects of a two-phase oil-water mouthwash on halitosis. Clin Prev Dent 1992 Jan-Feb;14(1):5-9.

17. Use of Olive Oil in the Preparation of a Product for Oral Hygiene For Eliminating or Reducing Bacterial Plaque and/ or Bacteria in the Mouth. United States Patent. Patent NO. US 7, 074, $391 \mathrm{~B} 1$.

18. Attin T, Knöfel S, Buchalla W, Tütüncü R. In situ evaluation of different remineralization periods to decrease brushing abrasion of demineralized enamel. Caries Res 2001 May-Jun;35(3):216-222.

19. Attin T, Siegel S, Buchalla W, Lennon AM, Hannig C, Becker K. Brushing abrasion of softened and remineralised dentin: an in situ study. Caries Res 2004 Jan-Feb;38(1):62-66.

20. Kitchens M, Owens BM. Effect of carbonated beverages, coffee, sports and high energy drinks, and bottled water on the in vitro erosion characteristics of dental enamel. J Clin Pediatr Dent 2007 Spring;31(3):153-159.

21. Devlin H, Bassiouny MA, Boston D. Hardness of enamel exposed to coca-cola and artificial saliva. J Oral Rehabil 2006 Jan;33(1):26-30. 
22. Brand HS, Tjoe Fat GM, Veerman EC. The effects of saliva on the erosive potential of three different wines. Aust Dent $\mathrm{J} 2009$ Sep;54(3):228-232.

23. Gilmour AG, Beckett HA. The voluntary reflux phenomenon. Br Dent J 1993 Nov;175(10):368-372.

24. Ren, YF. Dental erosion: etiology, diagnosis and prevention. A Peer-Reviewed Publication; 2011.

25. Jones RR, Cleaton-Jones P. Depth and area of dental erosions, and dental caries, in bulimic women. J Dent Res 1989 Aug;68(8):1275-1278.

26. Ganss C, Schlueter N, Hardt M, Schattenberg P, Klimek J. Effect of fluoride compounds on enamel erosion in vitro: A comparison of amine, sodium and stannous fluoride. Caries Res 2008;42:2-7.

27. West NX, Hughes JA, Parker DM, Newcombe RG, Addy M. Development and evaluation of a low erosive blackcurrant juice Drink 2. Comparison with a conventional blackcurrant juice drink and orange juice. J Dent 1999 Jul;27(5):341-344.

28. West NX, Hughes JA, Parker DM, Moohan M, Addy M. Development of low erosive carbonated fruit Drinks 2. Evaluation of an experimental carbonated blackcurrant drink compared to a conventional carbonated drink. J Dent 2003 Jul;31(5):361-365.

29. Ramberg P, Furuichi Y, Volpe AR, Gaffar A, Lindhe J. The effects of antimicrobial mouthrinses on de novo plaque formation at sites with healthy and inflamed gingivae. J Clin Periodontol 1996 Jan;23(1):7-11.

30. Ganss C, Klimek J, Schäffer U, Spall T. Effectiveness of two fluoridation measures on erosion progression in human enamel and dentine in vitro. Caries Res 2001 Sep-Oct;35(5):325-330.

31. Gedalia I, Braustein E, Lewinstein I, Shapira L, Ever-Hadani P, Sela M. Fluoride and hard cheese exposure on etched enamel in neck-irradiated patients in situ. J Dent 1996 Sep;24(5): 365-368.

32. Buchalla W, Attin T, Roth P, Hellwig E. Influence of olive oil emulsions on dentin demineralization in vitro. Caries Res 2003 Mar-Apr;37(2):100-107.

33. Slomiany BL, Murty VL, Mandel ID, Sengupta S, Slomiany A. Effect of lipids on the lactic acid retardation capacity of tooth enamel and cementum pellicles formed in vitro from saliva of caries-resistant and caries-susceptible human adults. Arch Oral Biol 1990;35(3):175-180. 